\title{
Presentation \\ Philosophy and Psychopathology : Phenomenological Perspectives
}

\author{
Elisabetta Basso \\ Centro de Filosofia \\ Universidade de Lisboa \\ Elisabetta.basso@campus.ul.pt
}

Over the last twenty years, we have been witnessing in the international context the emergence of what is presented as a "new research domain" within the philosophical field, the so-called "philosophy of psychiatry". In order to define this new domain, the Anglo-American authors, in particular, go back to Karl Jaspers' Allgemeine Psychopathologie and his attempt, at the beginning of the 20th century, to re-found psychopathology on the basis of the phenomenological method. Indeed, according to this view, "philosophy of psychiatry" would come to exist together with an appeal to phenomenology, in order to provide psychiatry with a systematic method for investigating the psychopathological phenomena. Now, in fact, the perspectives labelling themselves as "phenomenological" in psychopathology are quite heterogeneous, and it is necessary to study them thoroughly, from both an epistemological and historical point of view, if we actually want to understand and benefit from them at present.

However, it is possible to identify some general common features in the approaches adopted by the psychiatrists who have turned to one of the diverse models of phenomenology in order to reform their discipline from a theoretical point of view. Among these common traits stands out, first of all, the purpose of facing the observed phenomena without any prejudice, regardless of any medical-scientific judgment and independently from the existing clinical $\mathrm{nd} / 3.0 /)$. 
classifications. Secondly, the global or "structural" approach in face of the psychopathological manifestations should be mentioned, manifestations which are understood not as symptoms of a disease unrelated to each other, but as parts of a totality of sense that the psychiatrist has the task of bringing to light together with the patient. Finally, this general theoretical approach is guided by a fundamental anthropological concern.

The expectations of psychiatrists towards the diverse phenomenological models have changed over the time. From the 1920s to the 1950s, theorists of this approach saw in the phenomenological method the possibility of grounding psychiatric knowledge on new scientific bases, as "objective" as those of other medical disciplines. Ludwig Binswanger's Daseinsanalysis, for instance, far from being the mere adjustment of, respectively, Husserl's and Heidegger's phenomenological programs with the demand of a vaguely humanistic reform of psychiatry, tried to engage them in the field of psychopathology in order to establish a suitable method for this discipline. In turn, psychopathology has been a sort of testing ground for phenomenology's theoretical and methodological principles and method. As the French philosopher Henri Maldiney wrote in a letter to the Swiss psychiatrist Roland Kuhn in 1953, without the "renitence of the facts", phenomenology would be mere "intellectual agility", and it would just represent the "views of the State Major" against "the experience of the troop". This is also the reason why we have chosen as title of the present special issue "Philosophy and psychopathology", rather than "philosophy of psychopathology", in order to emphasize the reciprocity between these research domains.

Throughout the 1960s and 1970s, in countries like England, Italy and also Germany, phenomenological psychopathology, especially its "existential" variant, had an important weight for the development of the critical movements against institutional psychiatry. Although it would probably be risky to assert, as Henri Maldiney did, that "if the phenomenological attitude had prevailed in

\footnotetext{
${ }^{1}$ H. Maldiney, R. Kunn, Rencontre - Begegnung. Au péril d'exister. Briefwechsel / Correspondance 1953-2004, Liselotte Rutishauser, Robert Christe (Hrsg.), Würzburg: Königshausen \& Neumann, 2017, p. 26.
} 
psychiatry, antipsychiatry would not be born",2, it is undeniable that for the antipsychiatrists, as well as for some representatives of reform movements-like especially the "Sozialpsychiatrie" developed in the German Federal Republic from the 1970s-phenomenological psychopathology has become an instrument of reflection on the social dimension of psychic suffering and has given substance to reforms concerning the modalities of psychiatric patients' care. One of the reasons for this connection of positions that seem to be at first sight so distant from each other has been highlighted by the French psychiatrist Georges Lanteri-Laura. He showed that if phenomenology, in its different expressions, eventually lent its intuitions and even its arguments to the antipsychiatric movement, it is above all because it presents itself not as a doctrine, but as a fundamental "attitude" capable of finally putting aside any preliminary theoretical position about psychopathological phenomena ${ }^{3}$. In other words, phenomenology puts into question the legitimacy of any "interpretation" and "reductive choice" made on a subject that always appears, on the contrary, as a historical being.

During the 2000, "philosophers of psychiatry" have mostly emphasized a strictly conceptual approach, mirroring the changes that have occurred in the past twenty years in some areas of the Anglo-American philosophical thought, especially due to the implementation of concrete interactions with empirical knowledge such as biology, and particularly neuroscience. In this vein, several attempts have been made to renew the phenomenological approach in psychiatry according to the desiderata of this new scientific trend, so that some of the leading ideas in phenomenological psychopathology may be reassessed in the light of the main epistemological questions raised by contemporary philosophy of mind ${ }^{4}$.

\footnotetext{
${ }^{2}$ H. MALdiney, "Psychose et presence" (1976), in: Penser l'homme et la folie. À la lumière de l'analyse existentielle et de l'analyse du destin, Grenoble, Jérôme Millon, 1991, p. 5-82 (p. 9).

3 G. LANTERI-LAURA, "Le Voyage dans l'anti-psychiatrie anglaise”, L'Évolution psychiatrique, 61, 3 (1996), p. 621-633 (p. 623).

${ }^{4}$ See E. BASSO, "Où va la philosophie de la psychiatrie?", Revue de synthèse, 137, 1-2 (2016), p. 153-175, and C. ABETTAN, E. BASSO, "Quel renouveau pour la phénoménologie psychiatrique? Débat entre Elisabetta Basso et Camille Abettan, animé par Steeves Demazeux", PSN, 16, 1, 17-31.
} 
What about today? How does phenomenological psychopathology matter today? This is exactly the question we asked to the contributors of the present publication, and each of them develops a number of central issues of the present-day international debate.

In the opening paper, Camille Abettan goes straight to the heart of the matter by presenting both a historical and epistemological questioning about the specific object of "psychiatric phenomenology". He argues that in the field of psychopathology the original Husserlian project of "going back to the things themselves" has proven to be inadequate. This is the reason why one should better consider psychiatric phenomenology as closer to the field of hermeneutics, as defined by Ricoeur and Gadamer. Indeed, according to Abettan, the phenomenology of "what is seen" in psychiatry is not exclusively peculiar to the thing, but it rather regards the experience of the encounter between us and what is given in clinical experience. Thus, the phenomenological attitude, in psychiatry, should be conceived as just one of the forms that the clinical encounter can take, a form mediated by a cultural and historical tradition.

In her contribution on "Quiet and disquiet: the paradox of the lived time", Irene Borges-Duarte adopts a Heideggerian framework in order to investigate the experience of time at the level of the everyday being-in-the-world, and its pathological derivates. The core of Borges-Duarte's investigation is a methodological one, insofar as it emphasizes the distinction between, respectively, the psychological, and the ontological account concerning the concept of "lived time". Moods such as stress, boredom, and the joy of the present moment are not only emotional states, rather, they should be examined using a phenomenological approach aimed at revealing the pre-intentional dimension that underlies them. Differently from Husserl's view of the "immanent consciousness of time", our experience of time, according to Borges-Duarte, is a "living totality, a dynamic articulation of existence".

Maren Wehrle puts into question a quite common criticism that is made against phenomenology, according to which phenomenology's descriptions of normal experience cannot adequately account for psychopathological phenomena. Differently from this view, Wehrle's argument draws on Husserl's account of normality as a constitutive factor for experience - at both an individual, and an intersubjective level-, by emphasizing its "genetic" or 
dynamic nature. Indeed, according to Husserl, deviations and modifications from normality are needed to establish normality as such. At the core of Wehrle's analysis are the criteria of the "concordance" and "optimality" of experience, which intervene in the constitution of a common world as a tacit basis for joint action and communication. In order to substantiate her argument, Wehrle takes as examples the phenomena of schizophrenia and depression, by phenomenologically tracing back their major symptoms to fundamental disturbances of the temporal organization of experience.

The fundamental importance of the pre-reflexive or "tacit" dimension of experience is highlighted also by Sarah Troubé, whose investigation focuses on the concept of "trust" in both the fields of psychopathology and care ethics. By emphasizing the paradoxical and hybrid character of this concept between the ethical, the social, the political, the cognitive and the epistemic registers, Troubé's phenomenological approach questions the various facets in which trust is likely to manifest itself in psychopathological phenomena as a subjective experience and as a crucial phenomenon of the intersubjective structure of being in the world. In particular, three questions are explored: the first on the possibility of characterizing the pre-reflexive horizon of familiarity or natural evidences as trust; the second on the relationship between trust and empathy; and the third on the possibility of founding trust on anything other than an ideal of transparency, and its impact on a different characterization of trust in psychopathological manifestations and care relationships.

The passage accomplished by the phenomenological perspective from the cognitive and epistemic dimension of experience to the pre-reflexive one is also at the core of Till Grohmann's contribution, which dwells, in particular, upon the phenomena of delusion and hallucination in schizophrenia. Starting with a criticism against the current definitions of these phenomena given by the DSM5, Grohmann's aim is to reject the traditional (philosophical and medical) idea that delusion only deals with thought, and hallucinations with perceptual processes, in order to open a wider and global access to subjectivity and corporeity. According to Grohmann, the phenomenological approach-which the author draws from Jaspers, Minkowski, Ey, and Merleau-Ponty-is able to open an original way of approaching the concepts of pathology and symptoms.

The topic of corporeity and, more specifically, of the "lived body" is also central in Thomas Fuch's investigation on "Body memory of pain and trauma". 
The argument developed in this paper is that the lived body develops a memory of its painful experiences. Fuchs attributes such connection to a memory system that is independent of conscious memory, and should be rather defined as an implicit memory or, as he calls it, a "body memory". Now, since the body is built together with its habits in an environment, the body memory-while making environment familiar - is at the same time a memory of space and of situations ("protentional" memory). By illustrating the phenomenon of the memory of pain as the basis of both the self-experience, and the incorporation of the other, Fuchs eventually develops a phenomenological-corporeal understanding of the unconscious.

In his article on "Anxiety and body in Maine de Biran", Luís António Umbelino begins by a commentary on some passages of the French philosopher's Journal in order to investigate the phenomenon of anxietymore specifically, agoraphobic anxiety - in its relationship with the "affective body". According to Umbelino, Maine de Biran's descriptions evoke some central topics of the present-day phenomenologically-oriented research in the field of psychopathology. In particular, he emphasizes the connection between anxiety and motility of the body, the concept of one's own body", the intersubjective dimension of our being in the world, and the limits of selfconsciousness. What mostly interests Umbelino's phenomenological account for the experience of agoraphobia is the phenomenon of the loss of the body's "tacit", "silent" or "pre-reflective" being in the world.

The paper of Jérôme Englebert is a contribution from a phenomenologically-oriented perspective to the ecological approach to the borderline personality disorder. Englebert investigates the latter under the light of the notion of "limit situation" as defined by Jaspers. Drawing inspiration from Gabriel Marcel's reading of Jaspers' philosophy, Englebert dwells upon the five limit situations described by him (the historical situation, the love conflict, suffering, guilt, and death) in order to grasp their structural, "positive" features, that is, a specific temporality characterized by instantaneity and immediacy, and a specific relationship to the other.

Philippe Cabestan focuses on the debate dating from the beginning of the 1930s between Ludwig Binswanger and Erwin Straus about the relationship between the "Event and the sense of the event". The question put by Cabestan via these two authors is the following: how far does the sense of an event 
depend on the subject who lives it? Although both Binswanger and Straus reject the idea that there is a causal relationship between an event and the way it is lived, Binswanger criticizes Straus's idea that some events impose their sense. Special emphasis is given to the phenomenon of trauma. After discussing the two positions, Cabestan draws from Merleau-Ponty and eventually argues that our embodied being-in-the-world is prior to our sense-giving choices.

The contribution of Grégory Cormann presents itself as an original account of Sartre's position toward medicine and disease. Focusing on some unpublished works of the 1960s on ethics and, more specifically, by examining Sartre's reaction to the infanticide trial held in Liège in 1962 (the "Softenon trial"), Cormann investigates Sartre's concept of "pure possibility". The challenge of this article is to test this concept by especially emphasizing Sartre's idea of history, as well as the distance of Sartre's position from those sociological views, which in the infanticide case of Liège saw only individual madness or social pathology.

The idea of publishing this special issue comes from an international workshop organized in April 2018 at the Center of Philosophy of the University of Lisbon, thanks to the support of the same Center, the Faculty of Letters of the University of Lisbon, and the Fundação para a Ciência e a Tecnologia (FCT). The discussions were so rich and stimulating that we decided to involve further participants and publish their contributions. We wish to thank the Center of Philosophy of the University of Lisbon, as well Professor Pedro Alves and the research group he leads on phenomenological investigation for giving us the opportunity to publish these papers in the international journal Phainomenon. 